\title{
SISTEM PENDUKUNG KEPUTUSAN KARYAWAN TELADAN PT. BANK RAKYAT INDONESIA DENGAN METODE SIMPLE ADDITIVE WEIGHTING
}

\author{
Jodhy Prayogo \\ Sistem Informasi \\ STMIK Nusa Mandiri Jakarta \\ www.nusamandiri.ac.id \\ jodhy.prayogo@gmail.com
}

\begin{abstract}
In the decision making of exemplary employees, PT Bank Rakyat Indonesia conducts in several ways, namely, taking an assessment of absenteeism per three months, and individual assignments given by the supervisor. Data obtained after that must be processed back into an assessment to produce a model employee's decision. Data is collected for collection of types of criteria such as attendance assessment, assessment of individual assignments from the results of the combined assessment data. Data will be processed manually with a data processing application from Microsoft Excel. After processing it into the assessment data, the data will be checked again, the appropriate data will be given directly to the head of the department for the selection of quarterly exemplary employees. the existence of the Simple Additive Weighting (SAW) method can determine with many criteria in making an exemplary employee assessment decision and the time needed in data processing will also be faster and more efficient. The purpose of this study is to help companies in the process of selecting exemplary employees For the greatest value on Attendance criteria is an alternative A4 or employee on behalf of Nur Hidayatullah, for the largest value on Productivity criteria is alternative A27 selected employees are Urfani Meigasari, while for criteria on individual Tasks values the biggest on alternative A26 or selected employees is Denny Septian, for the biggest value with the criteria of responsibility on the alternative A27 the selected employees are Urfani Meigasari and for the largest value of the Supervisor Assessment criteria on the alternative A27 the selected employees are Urfani Meigasari.

Keywords: Decision Support Systems, Exemplary Employees, Simple Additive Weighting
\end{abstract}

\begin{abstract}
Abstrak-Dalam pengambilan keputusan karyawan teladan, PT Bank Rakyat Indonesia melakukan dengan beberapa cara yaitu, mengambil penilaian dari absensi per tiga bulan, dan tugas individual yang diberikan oleh supervisor. Data yang diperoleh setelah itu harus diolah kembali menjadi penilaian untuk menghasilkan keputusan karyawan teladan. Data dikumpulkan untuk dilakukan pengumpulan dari jenis kriteria- kriteria seperti penilaian absensi, penilaian tugas individual dari hasil data-data penilaian gabungan tersebut data akan diolah manual dengan aplikasi pengolah data dari Microsoft Excel. Setelah diolah menjadi data penilaian lalu data tersebut akan di cek kembali, data yang sudah sesuai akan diberikan langsung ke kepala bagian untuk dilakukan pemilihan karyawan teladan pertriwulan. adanya metode Simple Additive Weighting (SAW) ini dapat menentukan dengan banyak kriteria dalam membuat suatu keputusan penilaian karyawan teladan serta waktu yang dibutuhkan dalam pemrosesan data juga akan lebih cepat dan efisien. Tujuan penelitian ini untuk membantu perusahaan dalam proses pemilihan karyawan teladan Untuk nilai terbesar pada kriteria Absensi adalah alternatif A4 atau karyawan atas nama Nur Hidayatullah, untuk nilai terbesar pada kriteria Produktifitas adalah alternatif A27 karyawan yang terpilih adalah Urfani Meigasari, sedangkan untuk kriteria pada Tugas individual nilai terbesar pada alternatif A26 atau karyawan yang terpilih adalah Denny Septian, untuk nilai terbesar dengan kriteria tanggung jawab pada alternatif A27 karyawan yang terpilih adalah Urfani Meigasari dan untuk nilai terbesar dari kriteria Penilaian Supervisor pada alternatif A27 karyawan yang terpilih adalah Urfani Meigasari.
\end{abstract}

Kata Kunci: Sistem Penunjang Keputusan, Karyawan Teladan, Simple Additive Weighting

\section{PENDAHULUAN}

Dalam pengambilan keputusan karyawan teladan, PT Bank Rakyat Indonesia melakukan dengan beberapa cara yaitu, mengambil penilaian dari absensi per tiga bulan, dan tugas individual yang diberikan oleh supervisor. Data yang diperoleh setelah itu harus diolah kembali menjadi penilaian untuk menghasilkan keputusan karyawan teladan. Data dikumpulkan untuk dilakukan pengumpulan dari jenis kriteria- kriteria seperti penilaian absensi, penilaian tugas 
individual dari hasil data-data penilaian gabungan tersebut data akan diolah manual (Oktaviani, Merlina, \& Nurmalasari, 2018) dengan aplikasi pengolah data dari Microsoft Excel (Frieyadie, 2016). Setelah diolah menjadi data penilaian lalu data tersebut akan di cek kembali, data yang sudah sesuai akan diberikan langsung ke kepala bagian untuk dilakukan pemilihan karyawan teladan pertriwulan. Penilaian ini dilakukan subjektif hanya oleh kepala bagian saja

Terkadang cara tersebut kurang efektif (Erwandi, Mulyani, \& Senjaya, 2018) karena data yang didapat harus diolah terlebih dahulu dengan aplikasi pengolah data seperti Microsoft Excel (Frieyadie, 2016) yang dapat menyebabkan kesalahan dalam penginputan nilai yang akan diolah, dan dengan menggunakan proses manual (Octavia \& Yanto, 2014), (Ariato \& Siahaan, 2018) tersebut akan terasa lama (Suheryana, Sanjaya, \& Shobary, 2016) dan tidak efisien dalam menentukan karyawan teladan. Dengan menggunakan proses manual (Priahatin, 2016) tersebut akan terasa lama dan tidak efisien dalam menentukan karyawan teladan. Kriteria - kriteria dalam menentukan karyawan teladan PT Bank Rakyat Indonesia di Divisi Layanan dan Contact Center yaitu : kriteria absensi, produktifitas, penilaian dari supervisor, penilaian tugas individual untuk melakukan perubahan nilai atau permasalahan dari unit kerja, dan tanggung jawab. Kriteria-kriteria tersebut memungkinkan didalam penilaian untuk menentukan peringkat setiap karyawan sesuai dengan kualitas karyawan itu sendiri. Dan dengan menggunakan metode simple additive weighting perusahaan dapat melakukan penilaian untuk nilai-nilai karyawan teladan dengan akurat (Murtina, 2015). Tujuan penelitian ini untuk membantu perusahaan dalam proses pemilihan karyawan teladan. Memberikan solusi dengan menerapkan metode Simple Additive Weighting (SAW) yang dapat menentukan banyak kriteria dalam membuat suatu keputusan penilaian karyawan teladan. Memperbaiki pengolahan data penilaian dan menjadi pertimbangan agar lebih efisien. Untuk media penentu dalam memilih dan menentukan karyawan yang berkualitas.

\section{BAHAN DAN METODE}

\section{A. Instrument Penelitian}

Instrument merupakan alat yang digunakan untuk melakukan sesuatu. Sedangkan penelitian memiliki arti pemeriksaan, penyidikan, kegiatan pengumpulan, pengolahan, analisis dan penyajian data secara sistematis serta objektif. Penelitian ini menggunakan instrument kuesioner yang ditujukan langsung kepada supervisor di Divisi Layanan PT Bank Rakyat Indonesia untuk penentuan karyawan teladan. Pada data kuesioner tersebut berupa kriteria - kriteria dalam penentuan karyawan teladan. Setelah melakukan wawancara penulis mendapatkan 5 variabel dalam menentukan karyawan teladan, 5 variabel tersebut yaitu :

Tabel 1. Tabel Variabel Penelitian

\begin{tabular}{cl}
\hline Kriteria & \multicolumn{1}{c}{ Nama Kriteria } \\
\hline $\mathrm{C}_{1}$ & Absensi \\
\hline $\mathrm{C}_{2}$ & Produktifitas \\
\hline $\mathrm{C}_{3}$ & Tugas Individual \\
\hline $\mathrm{C}_{4}$ & Tanggung Jawab \\
\hline $\mathrm{C}_{5}$ & Penilaian Supervisor
\end{tabular}

Sumber: (Prayogo, 2017)

\section{B. Metode Pengumpulan Data \\ Dalam pengumpulan data penulis} menggunakan metode sebagai berikut:

\section{Metode Pengumpulan Data}

Dalam melakukan penelitian dibutuhkan data yang relevan, oleh karena itu penulis melakukan berbagai cara dalam mendapatkan informasi. Dan dalam pembuatan skripsi ini metode pengumpulan data yang penulis gunakan adalah :

a. Data Primer

Data primer adalah data yang langsung dikumpulkan oleh penulis dan data dikumpulkan langsung dari sumber pertama atau tempat objek penelitian dilakukan, data primer juga dapat diartikan sebagai data yang diperoleh dari sumber-sumber asli atau dari sumber pertama kali diperoleh. pengumpulan data primer dalam penelitian ini menggunakan metode obervasi dan wawancara.

b. Data Sekunder

Dalam pengumpulan data sekunder ini yang menjadi sumber data sekunder adalah buku, jurnal, e-book, dan lain-lain. Dan penulis mengumpulkan data sekunder yang didapat melalui study pustaka yang diperoleh dari literatur, jurnal, buku referensi yang berkenaan dengan penelitian yang dilakukan.

\section{Populasi}

Populasi adalah wilayah generalisasi yang terdiri atas obyek atau subyek yang mempunyai kualitas dan karakteristik tertentu yang ditetapkan oleh peneliti untuk dipelajari kemudian ditarik kesimpulannya (Sugiyono, 2015). Populasi dalam penelitian ini adalah data pegawai pada Divisi Layanan Dan Contact Center dalam menentukan karyawan teladan yang terdaftar di PT Bank 
Rakyat Indonesia dengan jumlah 35 karyawan periode tahun 2017. Tujuan diadakannya populasi adalah agar dapat menentukan besarnya sampel yang diambil dari jumlah populasi.

\section{Sample Penelitian}

Sample pada penelitian ini berdasarkan dari tabel isaac dan michael dengan tingkat kesalahan ditetapkan sebesar 5\% diperoleh jumlah sampel adalah sebesar 32 karyawan. Sedangkan untuk teknik pengambilan sampel penulis menggunakan Probability Sampling yaitu memberikan peluang yang sama pada setiap populasi untuk di pilih menjadi anggota sampel.

Tabel 1. Data Karyawan PT Bank Rakyat Indonesia Divisi Layanan Periode Tahun 2017

\begin{tabular}{|c|c|c|c|c|c|c|c|}
\hline No & Nama Pekerja & Supervisor & $\begin{array}{c}\text { Jenis } \\
\text { Kelamin }\end{array}$ & Tanggal Lahir & $\begin{array}{l}\text { Personal } \\
\text { Number }\end{array}$ & Agama & $\begin{array}{c}\text { Status } \\
\text { Pernikahan }\end{array}$ \\
\hline 1 & $\begin{array}{l}\text { Wiata Prima } \\
\text { Thasajati }\end{array}$ & Darwanto & $\mathrm{L}$ & $27 / 03 / 1985$ & 90046821 & Islam & Menikah \\
\hline 2 & Erna Widiastuti & Darwanto & $\mathrm{P}$ & $16 / 04 / 1987$ & 90056517 & Islam & Menikah \\
\hline 3 & $\begin{array}{l}\text { Muhamad } \\
\text { Lutfiansyah }\end{array}$ & Darwanto & $\mathrm{L}$ & 05/09/1989 & 90037429 & Islam & Belum Menikah \\
\hline 4 & Nur Hidayatullah & Darwanto & $\mathrm{L}$ & $27 / 11 / 1989$ & 90085379 & Islam & Belum Menikah \\
\hline 5 & M Fahmi Rizki & Darwanto & $\mathrm{L}$ & $12 / 10 / 1989$ & 90103467 & Islam & Belum Menikah \\
\hline 6 & Anik Puji Lestari & Darwanto & $\mathrm{P}$ & 02/08/1992 & 90046890 & Islam & Belum Menikah \\
\hline 7 & Deri Arianto & Darwanto & $\mathrm{L}$ & $27 / 03 / 1990$ & 90107652 & Islam & Menikah \\
\hline 8 & Lisa Sulistyarini & Darwanto & $\mathrm{P}$ & $05 / 02 / 1991$ & 90101857 & Islam & Belum Menikah \\
\hline 9 & Hafizh Qalam & Darwanto & $\mathrm{L}$ & $27 / 10 / 1993$ & 90054200 & Islam & Belum Menikah \\
\hline 10 & $\begin{array}{l}\text { Muhamad Budi } \\
\text { Pamuji }\end{array}$ & Irwan S. & $\mathrm{L}$ & $25 / 07 / 1991$ & 90106542 & Islam & Belum Menikah \\
\hline 11 & Nasfridona & Irwan S. & $\mathrm{L}$ & $20 / 04 / 1989$ & 90122291 & Islam & Belum Menikah \\
\hline 12 & Andi Riyanto & Irwan S. & $\mathrm{L}$ & 08/03/1988 & 90100289 & Islam & Belum Menikah \\
\hline 13 & Frengki Tumpal & Irwan S. & $\mathrm{L}$ & $16 / 04 / 1983$ & 90047842 & Kristen & Menikah \\
\hline 14 & $\begin{array}{l}\text { Rahmat Salim } \\
\text { Rumnie }\end{array}$ & Irwan S. & $\mathrm{L}$ & $11 / 07 / 1988$ & 90092752 & Islam & Belum Menikah \\
\hline 15 & $\begin{array}{l}\text { Risky Aditya } \\
\text { Salatin }\end{array}$ & Irwan S. & $\mathrm{L}$ & $23 / 07 / 1993$ & 90046138 & Islam & Belum Menikah \\
\hline 16 & Lesly Wuisang & Irwan S. & $\mathrm{L}$ & 28/08/1989 & 90079196 & Kristen & Belum Menikah \\
\hline 17 & Mohamad Andika & Irwan S. & $\mathrm{L}$ & $17 / 02 / 1991$ & 90071468 & Islam & Belum Menikah \\
\hline 18 & Achmad Faisal & Adhi C & $\mathrm{L}$ & $23 / 02 / 1987$ & 90071458 & Islam & Belum Menikah \\
\hline 19 & Mita Erlina & Adhi C. & $\mathrm{P}$ & $02 / 12 / 1986$ & 90104736 & Islam & Menikah \\
\hline 20 & $\begin{array}{l}\text { Nahlah Zafira } \\
\text { Lestari }\end{array}$ & Adhi C. & $\mathrm{P}$ & $24 / 05 / 1992$ & 90104737 & Islam & Menikah \\
\hline 21 & Afriza & Adhi C. & $\mathrm{L}$ & 09/09/1988 & 90105472 & Islam & Menikah \\
\hline 22 & Irawan Sapto Aji & Adhi C. & $\mathrm{L}$ & 19/09/1988 & 90105665 & Islam & Belum Menikah \\
\hline 23 & Zakaria & Adhi C. & $\mathrm{L}$ & $12 / 10 / 1986$ & 90106021 & Islam & Menikah \\
\hline 24 & Denny Septian & Adhi C. & $\mathrm{L}$ & $04 / 02 / 1987$ & 90105781 & Islam & Belum Menikah \\
\hline 25 & Melisa Sitepu & Heri S. & $\mathrm{P}$ & $13 / 06 / 1989$ & 90106809 & Kristen & Belum Menikah \\
\hline 26 & Ade Febi Damanik & Heri S. & $\mathrm{L}$ & $27 / 03 / 1992$ & 90109333 & Kristen & Belum Menikah \\
\hline 27 & Urfani Meigasari & Heri S. & $\mathrm{P}$ & $11 / 06 / 1990$ & 90106812 & Islam & Menikah \\
\hline 28 & Herman & Heri S. & $\mathrm{L}$ & $03 / 08 / 1986$ & 90050473 & Islam & Menikah \\
\hline 29 & Rahma Wulandari & Heri S. & $\mathrm{P}$ & $24 / 08 / 1987$ & 90102070 & Islam & Menikah \\
\hline 30 & Jodhy Prayogo & Heri S. & $\mathrm{L}$ & 02/12/1991 & 90022201 & Islam & Belum Menikah \\
\hline 31 & Putri Safrita & Heri S. & $\mathrm{P}$ & $11 / 07 / 1993$ & 90105568 & Islam & Belum Menikah \\
\hline 32 & Rena Isninna & Heri S. & $\mathrm{P}$ & $11 / 07 / 1994$ & 90090935 & Islam & Belum Menikah \\
\hline
\end{tabular}

Sumber: (Prayogo, 2017)

\section{Metode Analisis Data}

Dalam mencapai tujuan penelitian maka analisis yang digunakan adalah data kualitatif dengan menggunakan metode Simple Additive Weighting (SAW), metode ini merupakan metode yang paling sederhana dan paling banyak digunakan dan juga metode yang paling mudah untuk di aplikasikan.

\section{HASIL DAN PEMBAHASAN}

Menentukan karyawan teladan di PT Bank Rakyat Indonesia, dengan jumlah data pada penelitian ini 36 karyawan. Setiap karyawan disebut sebagai suatu alternatif (A1, A2, A3 dan seterusnya).

\section{A. Pengolahan Data dan Perhitungan Manual Dengan Metode SAW}


Dalam proses ini tahapan yang diperlukan dalam pengolahan data adalah sebagai berikut :

\section{Analisa Kebutuhan}

Analisa kebutuhan dapat dibagi menjadi dua bagian, yaitu analisa kebutuhan input dan analisa kebutuhan output. Untuk analisa kebutuhan input adalah variabel input yang digunakan untuk penelitian ini adalah: Absensi, Produktifitas, Tugas individual, Tanggung jawab, dan Penilaian supervisor. Sedangkan untuk analisa kebutuhan output pada penelitian ini adalah sebuah alternatif yang memiliki nilai tertinggi dibandingkan dengan alternatif nilai lain.

\section{Penyelesaian Menggunakan Metode SAW}

Pada tahap ini akan dilakukan pengujian terhadap hasil penelitian dengan menggunakan metode Simple Additive Weighting (SAW) yang digunakan dalam pengolahan data menentukan karyawan teladan pada PT Bank Rakyat Indonesia. Untuk melakukan perhitungan dalam menentukan karyawan teladan menggunakan metode Simple Additive Weighting (SAW) :

a. Langkah pertama menentukan alternatif, yaitu A1 berikut adalah data alternatif yang akan digunakan dalam perhitungan.

Tabel 2. Data Alternatif

\begin{tabular}{|c|c|c|c|c|c|c|}
\hline \multirow[t]{2}{*}{ No } & \multirow[t]{2}{*}{ Alternatif } & \multicolumn{5}{|c|}{ Kriteria } \\
\hline & & Absensi & Produktifitas & Tugas Individual & $\begin{array}{c}\text { Tanggung } \\
\text { Jawab }\end{array}$ & $\begin{array}{c}\text { Penilaian } \\
\text { Supervisor }\end{array}$ \\
\hline 1 & $\mathrm{~A}_{1}$ & 3 & 2 & 2 & 3 & 4 \\
\hline 2 & $\mathrm{~A}_{2}$ & 3 & 4 & 3 & 2 & 4 \\
\hline 3 & $\mathrm{~A}_{3}$ & 2 & 2 & 4 & 4 & 2 \\
\hline 4 & $\mathrm{~A}_{4}$ & 5 & 3 & 3 & 4 & 3 \\
\hline 5 & $\mathrm{~A}_{5}$ & 3 & 4 & 4 & 3 & 4 \\
\hline 6 & $A_{6}$ & 4 & 2 & 4 & 3 & 3 \\
\hline 7 & $\mathrm{~A}_{7}$ & 3 & 3 & 2 & 2 & 4 \\
\hline 8 & $\mathrm{~A}_{8}$ & 5 & 3 & 1 & 1 & 4 \\
\hline 9 & $\mathrm{~A}_{9}$ & 3 & 4 & 2 & 2 & 4 \\
\hline 10 & $\mathrm{~A}_{10}$ & 4 & 2 & 2 & 1 & 5 \\
\hline 11 & $\mathrm{~A}_{11}$ & 2 & 3 & 2 & 3 & 4 \\
\hline 12 & $\mathrm{~A}_{12}$ & 4 & 3 & 2 & 1 & 4 \\
\hline 13 & $\mathrm{~A}_{13}$ & 3 & 4 & 5 & 2 & 5 \\
\hline 14 & $\mathrm{~A}_{14}$ & 4 & 2 & 3 & 2 & 4 \\
\hline 15 & $\mathrm{~A}_{15}$ & 3 & 2 & 4 & 2 & 5 \\
\hline 16 & $\mathrm{~A}_{16}$ & 4 & 3 & 2 & 2 & 4 \\
\hline 17 & $\mathrm{~A}_{17}$ & 3 & 3 & 4 & 2 & 4 \\
\hline 18 & $\mathrm{~A}_{18}$ & 4 & 5 & 3 & 2 & 5 \\
\hline 19 & $\mathrm{~A}_{19}$ & 5 & 2 & 3 & 3 & 4 \\
\hline 20 & $\mathrm{~A}_{20}$ & 4 & 3 & 2 & 3 & 4 \\
\hline 21 & $A_{21}$ & 4 & 4 & 3 & 2 & 4 \\
\hline 22 & $\mathrm{~A}_{22}$ & 2 & 3 & 4 & 1 & 5 \\
\hline 23 & $\mathrm{~A}_{23}$ & 2 & 3 & 3 & 2 & 5 \\
\hline 24 & $\mathrm{~A}_{24}$ & 3 & 3 & 2 & 1 & 3 \\
\hline 25 & $A_{25}$ & 3 & 2 & 4 & 2 & 3 \\
\hline 26 & $\mathrm{~A}_{26}$ & 4 & 2 & 5 & 3 & 4 \\
\hline 27 & $\mathrm{~A}_{27}$ & 4 & 5 & 3 & 4 & 2 \\
\hline 28 & $\mathrm{~A}_{28}$ & 3 & 3 & 3 & 1 & 4 \\
\hline 29 & $\mathrm{~A}_{29}$ & 2 & 3 & 2 & 3 & 4 \\
\hline 30 & $\mathrm{~A}_{30}$ & 4 & 2 & 4 & 2 & 5 \\
\hline 31 & $A_{31}$ & 3 & 2 & 3 & 1 & 5 \\
\hline 32 & $\mathrm{~A}_{32}$ & 3 & 4 & 3 & 2 & 4 \\
\hline
\end{tabular}

Sumber: (Prayogo, 2017)

\section{b. Kriteria dan Bobot}

Dalam langkah kedua menentukan kriteria yang akan dijadikan acuan dalam pengambilan keputusan, yaitu C1. dan untuk dalam menentukan penilaian dibutuhkan kriteria, seperti Absensi, Produktifitas, Tugas individual, Tanggung jawab, dan Penilaian supervisor.

1) Absensi

2) Produktifitas
3) Tugas Individual

4) Tanggal Jawab

5) Penilaian Supervisor

Kelima kriteria memiliki nilai dan pembobotan untuk variabel absensi ditunjukan pada tabel 3 .

Tabel 3. Absensi

Bilangan Fuzzy Nilai




\begin{tabular}{ll}
\hline Kurang Sekali (KS) & 1 \\
\hline Kurang (K) & 2 \\
\hline Cukup (C) & 3 \\
\hline Baik (B) & 4 \\
\hline Baik Sekali (BS) & 5 \\
\hline Sumber: (Prayogo, 2017) &
\end{tabular}

c. Bobot Preferensi (W)

Dalam proses penentuan ini bobot preferensi atau tingkat kepentingan untuk setiap kriteria. Bobot kriteria yang digunakan untuk menentukan karyawan teladan pada PT. Bank Rakyat Indonesia sebagai berikut:

Tabel 4. Bobot Kepentingan Kriteria

\begin{tabular}{cc}
\hline Bobot $(\mathbf{W})$ & Keterangan \\
\hline 0,2 & Kurang Sekali \\
\hline 0,4 & Kurang \\
\hline 0,6 & Cukup \\
\hline 0,8 & Baik \\
\hline 1 & Baik Sekali \\
\hline
\end{tabular}

Sumber: (Prayogo, 2017)
Tabel 5. Tingkat Kepentingan (W)

\begin{tabular}{lcc}
\hline \multicolumn{1}{c}{ Kriteria (C) } & $\begin{array}{c}\text { Bobot } \\
\text { (W) }\end{array}$ & Keterangan \\
\hline $\mathrm{C} 1=$ Absensi & 1 & Baik Sekali \\
\hline $\mathrm{C}_{2}=$ Produktifitas & 0,6 & Cukup \\
\hline $\mathrm{C}_{3}=$ Tugas Individual & 0,8 & Baik \\
\hline $\mathrm{C}_{4}=$ Tanggung Jawab & 1 & Baik Sekali \\
\hline $\mathrm{C}_{5}=$ Penilaian Supervisor & 0,8 & Baik \\
\hline
\end{tabular}

Sumber: (Prayogo, 2017)

d. Nilai Rating Kecocokan Setiap Alternatif Pada Setiap Kriteria

Dalam menentukan rating kecocokan setiap alternatif pada setiap kriteria yang telah ditentukan pada tabel diatas ditunjukan pada Tabel 5.

Tabel 5. Rating Kecocokan Alternatif

\begin{tabular}{|c|c|c|c|c|c|c|}
\hline \multirow[t]{3}{*}{ No } & \multirow[t]{3}{*}{ Alternatif } & \multicolumn{5}{|c|}{ Kriteria } \\
\hline & & Absensi & Produktifitas & Tugas Individual & $\begin{array}{c}\text { Tanggung } \\
\text { Jawab }\end{array}$ & $\begin{array}{c}\text { Penilaian } \\
\text { Supervisor }\end{array}$ \\
\hline & & $\mathrm{C}_{1}$ & $\mathrm{C}_{2}$ & $\mathrm{C}_{3}$ & $\mathrm{C}_{4}$ & $\mathrm{C}_{5}$ \\
\hline 1 & $\mathrm{~A}_{1}$ & 3 & 2 & 2 & 3 & 4 \\
\hline 2 & $\mathrm{~A}_{2}$ & 3 & 4 & 3 & 2 & 4 \\
\hline 3 & $\mathrm{~A}_{3}$ & 2 & 2 & 4 & 4 & 2 \\
\hline 4 & $\mathrm{~A}_{4}$ & 5 & 3 & 3 & 4 & 3 \\
\hline 5 & $\mathrm{~A}_{5}$ & 3 & 4 & 4 & 3 & 4 \\
\hline 6 & $\mathrm{~A}_{6}$ & 4 & 2 & 4 & 3 & 3 \\
\hline 7 & $\mathrm{~A}_{7}$ & 3 & 3 & 2 & 2 & 4 \\
\hline 8 & $\mathrm{~A}_{8}$ & 5 & 3 & 1 & 1 & 2 \\
\hline 9 & $\mathrm{~A}_{9}$ & 3 & 4 & 2 & 2 & 4 \\
\hline 10 & $\mathrm{~A}_{10}$ & 4 & 2 & 2 & 1 & 3 \\
\hline 11 & $\mathrm{~A}_{11}$ & 2 & 3 & 2 & 3 & 4 \\
\hline 12 & $\mathrm{~A}_{12}$ & 4 & 3 & 2 & 1 & 4 \\
\hline 13 & $\mathrm{~A}_{13}$ & 3 & 4 & 5 & 2 & 5 \\
\hline 14 & $\mathrm{~A}_{14}$ & 4 & 2 & 3 & 2 & 4 \\
\hline 15 & $\mathrm{~A}_{15}$ & 3 & 2 & 4 & 2 & 5 \\
\hline 16 & $\mathrm{~A}_{16}$ & 4 & 3 & 2 & 2 & 4 \\
\hline 17 & $\mathrm{~A}_{17}$ & 3 & 3 & 4 & 2 & 4 \\
\hline 18 & $\mathrm{~A}_{18}$ & 4 & 5 & 3 & 2 & 5 \\
\hline 19 & $\mathrm{~A}_{19}$ & 5 & 2 & 3 & 3 & 4 \\
\hline 20 & $\mathrm{~A}_{20}$ & 4 & 3 & 2 & 3 & 4 \\
\hline 21 & $\mathrm{~A}_{21}$ & 4 & 4 & 3 & 2 & 4 \\
\hline 22 & $\mathrm{~A}_{22}$ & 2 & 3 & 4 & 1 & 3 \\
\hline 23 & $\mathrm{~A}_{23}$ & 2 & 3 & 3 & 2 & 4 \\
\hline 24 & $\mathrm{~A}_{24}$ & 3 & 3 & 2 & 1 & 3 \\
\hline 25 & $\mathrm{~A}_{25}$ & 3 & 2 & 4 & 2 & 3 \\
\hline 26 & $\mathrm{~A}_{26}$ & 4 & 2 & 5 & 3 & 4 \\
\hline 27 & $\mathrm{~A}_{27}$ & 4 & 5 & 3 & 4 & 5 \\
\hline 28 & $\mathrm{~A}_{28}$ & 3 & 3 & 3 & 1 & 4 \\
\hline 29 & $\mathrm{~A}_{29}$ & 2 & 3 & 2 & 3 & 4 \\
\hline 30 & $\mathrm{~A}_{30}$ & 4 & 2 & 4 & 2 & 5 \\
\hline 31 & $\mathrm{~A}_{31}$ & 3 & 2 & 3 & 1 & 3 \\
\hline
\end{tabular}




\begin{tabular}{lllllll}
\hline 32 & $\mathrm{~A}_{32}$ & 3 & 4 & 3 & 2 & 4 \\
\hline
\end{tabular}

$\frac{\mathrm{A}_{32}}{\text { Sumber: (Prayogo, 2017) }}$

e. Matriks Keputusan

Setelah nilai pada rating alternatif setiap kriteria sudah ditentukan di langkah selanjutnya membuat matrix keputusan (X) yang dibentuk dari tabel rating kecocokan yang didapat dari semua kriteria. Nilai (X) setiap alternatif (A1) pada setiap kriteria (C1) yang telah ditentukan.

\section{f. Normalisasi Keputusan (X)}

Proses selanjutnya adalah proses normalisasi keputusan (X) ke skala yang dapat dibandingkan dengan semua rating alternatif yang telah didapatkan.

$$
R_{i j}=\frac{X_{i j}}{\operatorname{Max} x_{i j}}
$$

\section{Nilai Preferensi (V1)}

Tabel 6. Hasil Pengujian

\begin{tabular}{|c|c|c|c|c|c|c|c|}
\hline \multirow{3}{*}{ No } & \multirow{3}{*}{ Alternatif } & \multicolumn{5}{|c|}{ Kriteria } & \multirow{3}{*}{$\begin{array}{l}\text { Hasil } \\
\text { Akhir }\end{array}$} \\
\hline & & Absensi & Produktifitas & Tugas Individual & $\begin{array}{c}\text { Tanggung } \\
\text { Jawab }\end{array}$ & $\begin{array}{c}\text { Penilaian } \\
\text { Supervisor }\end{array}$ & \\
\hline & & $\mathrm{C}_{1}$ & $\mathrm{C}_{2}$ & $\mathrm{C}_{3}$ & $\mathrm{C}_{4}$ & $\mathrm{C}_{5}$ & \\
\hline 1 & $\mathrm{~A}_{1}$ & 0.6 & 0.4 & 0.4 & 0.75 & 0.8 & 2.55 \\
\hline 2 & $\mathrm{~A}_{2}$ & 0.6 & 0.8 & 0.6 & 0.5 & 0.8 & 2.7 \\
\hline 3 & $\mathrm{~A}_{3}$ & 0.4 & 0.4 & 0.8 & 1 & 0.5 & 2.68 \\
\hline 4 & $\mathrm{~A}_{4}$ & 1 & 0.6 & 0.6 & 1 & 0.75 & 3.44 \\
\hline 5 & $\mathrm{~A}_{5}$ & 0.6 & 0.8 & 0.8 & 0.75 & 0.8 & 3.11 \\
\hline 6 & $\mathrm{~A}_{6}$ & 0.8 & 0.4 & 0.8 & 0.75 & 0.6 & 2.91 \\
\hline 7 & $\mathrm{~A}_{7}$ & 0.6 & 0.6 & 0.4 & 0.5 & 0.8 & 2.42 \\
\hline 8 & $\mathrm{~A}_{8}$ & 1 & 0.6 & 0.4 & 0.5 & 0.8 & 2.82 \\
\hline 9 & $\mathrm{~A}_{9}$ & 0.6 & 0.8 & 0.4 & 0.5 & 0.8 & 2.54 \\
\hline 10 & $\mathrm{~A}_{10}$ & 0.8 & 0.4 & 0.4 & 0.25 & 1 & 2.41 \\
\hline 11 & $\mathrm{~A}_{11}$ & 0.4 & 0.6 & 0.4 & 0.75 & 0.8 & 2.47 \\
\hline 12 & $\mathrm{~A}_{12}$ & 0.8 & 0.6 & 0.4 & 0.25 & 0.8 & 2.37 \\
\hline 13 & $\mathrm{~A}_{13}$ & 0.6 & 0.8 & 1 & 0.5 & 1 & 3.18 \\
\hline 14 & $\mathrm{~A}_{14}$ & 0.8 & 0.4 & 0.6 & 0.5 & 0.8 & 2.66 \\
\hline 15 & $\mathrm{~A}_{15}$ & 0.6 & 0.4 & 0.8 & 0.5 & 1 & 2.66 \\
\hline 16 & $\mathrm{~A}_{16}$ & 0.8 & 0.6 & 0.4 & 0.5 & 0.8 & 2.62 \\
\hline 17 & $\mathrm{~A}_{17}$ & 0.6 & 0.6 & 0.8 & 0.5 & 0.8 & 2.74 \\
\hline 18 & $\mathrm{~A}_{18}$ & 0.8 & 1 & 0.6 & 0.75 & 0.8 & 3.18 \\
\hline 19 & $\mathrm{~A}_{19}$ & 1 & 0.4 & 0.6 & 0.75 & 0.8 & 3.11 \\
\hline 20 & $\mathrm{~A}_{20}$ & 0.8 & 0.6 & 0.4 & 0.75 & 0.8 & 2.87 \\
\hline 21 & $A_{21}$ & 0.8 & 0.8 & 0.6 & 0.5 & 0.8 & 2.9 \\
\hline 22 & $\mathrm{~A}_{22}$ & 0.4 & 0.6 & 0.8 & 0.25 & 0.6 & 2.13 \\
\hline 23 & $\mathrm{~A}_{23}$ & 0.4 & 0.6 & 0.6 & 0.5 & 0.8 & 2.38 \\
\hline 24 & $\mathrm{~A}_{24}$ & 0.6 & 0.6 & 0.4 & 0.25 & 0.6 & 2.01 \\
\hline 25 & $\mathrm{~A}_{25}$ & 0.6 & 0.4 & 0.8 & 0.5 & 0.8 & 2.46 \\
\hline 26 & $\mathrm{~A}_{26}$ & 0.8 & 0.4 & 1 & 0.75 & 0.8 & 3.23 \\
\hline 27 & $\mathrm{~A}_{27}$ & 0.8 & 1 & 0.6 & 1 & 1 & 3.68 \\
\hline 28 & $\mathrm{~A}_{28}$ & 0.6 & 0.6 & 0.6 & 0.25 & 0.8 & 2.33 \\
\hline 29 & $A_{29}$ & 0.4 & 0.6 & 0.4 & 0.75 & 0.8 & 2.47 \\
\hline 30 & $A_{30}$ & 0.8 & 0.4 & 0.8 & 0.5 & 1 & 2.98 \\
\hline 31 & $A_{31}$ & 0.6 & 0.4 & 0.6 & 0.25 & 0.6 & 2.05 \\
\hline 32 & $\mathrm{~A}_{32}$ & 0.6 & 0.8 & 0.6 & 0.5 & 0.8 & 2.7 \\
\hline
\end{tabular}

Sumber: (Prayogo, 2017)

Pada proses terakhir adalah menghitung hasil akhir preferensi (V1) yang diperoleh dari penjumlahan dan perkalian elemen baris matriks ternormalisasi (R) dengan bobot preferensi (W) yang bersesuaian dengan elemen kolom matriks (R).

$$
V_{i}=\sum_{j=1}^{n} W_{j} r_{i j}
$$

Bobot Preferensi : 1, 0.6,0.8,1,0.8

Berikut hasil pengujian dimana nilai awal dari setiap alternatif diproses menggunakan metode Simple Additive Weighting (SAW) dan mendapatkan nilai hasil akhir dalam perhitungan seperti diatas, berikut tabel IV.10. 
Untuk nilai terbesar pada kriteria Absensi adalah alternatif A4 atau karyawan atas nama Nur Hidayatullah, untuk nilai terbesar pada kriteria Produktifitas adalah alternatif A27 karyawan yang terpilih adalah Urfani Meigasari, sedangkan untuk kriteria pada Tugas individual nilai terbesar pada alternatif A26 atau karyawan yang terpilih adalah Denny Septian, untuk nilai terbesar dengan kriteria tanggung jawab pada alternatif A27 karyawan yang terpilih adalah Urfani Meigasari dan untuk nilai terbesar dari kriteria Penilaian Supervisor pada alternatif A27 karyawan yang terpilih adalah Urfani Meigasari. Dari tabel 6, ini untuk nilai terbesar ada pada V27, sehingga untuk alternatif A27 atau karyawan yang terpilih menjadi karyawan teladan adalah Urfani Meigasari dengan penilaian 3,68. Namun pada kasus ini alternatif yang terbaik adalah beberapa karyawan yang mendapatkan nilai pembobotan cukup pada setiap kriteria.

\section{KESIMPULAN}

Berdasarkan uraian dan tinjauan dari pembahasan penelitian yang telah dilakukan, maka kesimpulan yang didapat dari penelitian yang telah dilakukan, proses penentuan karyawan terbaik PT Bank Rakyat Indonesia dengan metode SAW dimulai dengan pemberian nilai kriteria, pembobotan, rating kecocokan, normalisasi dan perangkingan. Sehingga menghasilkan nilai untuk masing - masing kriteria. Hasil dari perhitungan tersebut merupakan perangkingan nilai tertinggi ke nilai terendah, dan nilai tertinggi merupakan hasil yang dibutuhkan untuk menentukan karyawan terbaik. Untuk nilai terbesar pada kriteria Absensi adalah alternatif A4 atau karyawan atas nama Nur Hidayatullah, untuk nilai terbesar pada kriteria Produktifitas adalah alternatif A27 karyawan yang terpilih adalah Urfani Meigasari, sedangkan untuk kriteria pada Tugas individual nilai terbesar pada alternatif A26 atau karyawan yang terpilih adalah Denny Septian, untuk nilai terbesar dengan kriteria tanggung jawab pada alternatif A27 karyawan yang terpilih adalah Urfani Meigasari dan untuk nilai terbesar dari kriteria Penilaian Supervisor pada alternatif A27 karyawan yang terpilih adalah Urfani Meigasari Metode Simple Additive Weghting (SAW) dapat memberikan alternatif keputusan yang terbaik dalam pengambilan keputusan.

\section{REFERENSI}

Ariato, E. Y., \& Siahaan, F. B. (2018). ANALISA PENILAIAN KINERJA KARYAWAN DENGAN METODE FUZZY SIMPLE ADDITIVE
WEIGHTING Pada PT. Unilever Indonesia Tbk Skin Deo Factory SBU Production Tube. Jurnal Teknik Komputer, 4(1), 194-204. https://doi.org/10.31294/JTK.V4I1.2546

Erwandi, D., Mulyani, E. D. S., \& Senjaya, A. S. (2018). Sistem Pendukung Keputusan Untuk Penilaian Kinerja Guru Menggunakan Metode Weighted Product (Studi Kasus: Madrasah Ibtidaiyah Condong) | Erwandi | Konferensi Nasional Sistem Informasi (KNSI) 2018. In Konferensi Nasional Sistem Informasi (KNSI) 2018 (pp. 870-876). Pangkalpinang: STMIK Atma Luhur. Retrieved from http://jurnal.atmaluhur.ac.id/index.php/kns i2018/article/view/463

Frieyadie, F. (2016). Penerapan Metode Simple Additive Weight (SAW) Dalam Sistem Pendukung Keputusan Promosi Kenaikan Jabatan. Jurnal Pilar Nusa Mandiri, 12(1), 3745.

Murtina, H. (2015). SISTEM PENUNJANG KEPUTUSAN PEMILIHAN SUPERVISOR MENGGUNAKAN SIMPLE ADDITIVE WEIGHTING PADA PT NIPPON INDOSARI CORPINDO. Konferensi Nasional Ilmu Pengetahuan Dan Teknologi, 1(1), 143-148. Retrieved from http://konferensi.nusamandiri.ac.id/prosidi ng/index.php/knit/article/view/77

Octavia, E., \& Yanto, A. H. (2014). PENERAPAN METODE FUZZY PADA PENILAIAN KINERJA KARYAWAN (studi kasus PT. IndovisualJakarta). Jurnal Techno Nusa Mandiri, 11(2). Retrieved from http://ejournal.nusamandiri.ac.id/ejurnal/in dex.php/techno/article/view/96

Oktaviani, N., Merlina, N., \& Nurmalasari, N. (2018). Pemilihan Jasa Pengiriman Terbaik Menggunakan Metode Simple Additive Weighting (SAW). Jurnal Sistem Dan Teknologi Informasi (JUSTIN), 6(4), 219. https://doi.org/10.26418/justin.v6i4.29126

Prayogo, J. (2017). Laporan Tugas Akhir - Sistem Pendukung Keputusan Karyawan Teladan Pt. Bank Rakyat Indonesia Dengan Metode Simple Additive Weighting. Jakarta.

Priahatin, T. (2016). PENERAPAN METODE SIMPLE ADDITIVE WEIGHTING (SAW) UNTUK PENENTUAN STATUS PENGANGKATAN KARYAWAN. Seminar Nasional Ilmu Pengetahuan Dan Teknologi 
Komputer, 19-INF.24. Retrieved from http://konferensi.nusamandiri.ac.id/prosidi ng/index.php/sniptek/article/view/9

Sugiyono. (2015). Metode Penelitian Kuantitatif Kualitatif Dan R\&D. Bandu: Alfabeta.

Suheryana, M. D., Sanjaya, R., \& Shobary, M. N. (2016). SISTEM PENUNJANG KEPUTUSAN PENERIMAAN PEGAWAI BARU PADA PT. EBDESK TEKNOLOGI. Seminar Nasional Ilmu Pengetahuan Dan Teknologi Komputer, 63INF.68. Retrieved from http://konferensi.nusamandiri.ac.id/prosidi ng/index.php/sniptek/article/view/17 